This manuscript was accepted and published by Energy \& Fuels, a journal of the American Chemical Society. DOI: 10.1021/ef034030+ (http://pubs.acs.org/doi/abs/10.1021/ef034030\%2B ).

This manuscript was placed into the present public repository with the consent of the Editor of Energy \& Fuels. Publication data of the final, corrected work:

Mészáros, E.; Várhegyi, G.; Jakab, E.; Marosvölgyi, B.: Thermogravimetric and reaction kinetic analysis of biomass samples from an energy plantation. Energy Fuels 2004, 18, 497-507. doi: $\underline{10.1021 / \mathrm{ef} 034030+}$

\title{
Thermogravimetric and Reaction Kinetic Analysis of Biomass Samples from an Energy Plantation
}

\author{
Erika Mészáros, Gábor Várhegyi ${ }^{*}$ and Emma Jakab
}

Research Laboratory of Materials and Environmental Chemistry, Chemical Research Center, Hungarian Academy Sciences, P.O. Box 17, Budapest, 1525 Hungary

Béla Marosvölgyi

Institute of Energetics, University of West Hungary, P.O. Box 132, Sopron, 9400 Hungary

Keywords: Biomass, Wood, Thermal analysis, Kinetics, Short rotation forestry, Energy crops

Title running head: TG and Reaction Kinetic Analysis of Biomass Samples

\footnotetext{
${ }^{*}$ To whom correspondence should be addressed. Phone: +361438 4140. Fax: +3613257892.

E-mail: varhegyi.gabor@ttk.mta.hu
}

\begin{abstract}
The products of a Hungarian experimental plantation for energy crops were investigated. Young shoots of poplar clones (Populus $\times$ euramericana and Populus $\times$ interamericana), black locust (Robinia pseudoacacia), willow (Salix alba) and an herbaceous plant (Miscanthus sinensis) revealed unexpectedly similar thermal behavior in inert and oxidative atmospheres, as well. An eightfold difference in the level of grinding did not result in substantial differences in the thermal decomposition. The effect of oxygen in the ambient gas was studied at low sample masses $(0.2-0.4 \mathrm{mg})$ that excluded
\end{abstract}


the overheating due to the high reaction heat of the combustion process. The presence of oxygen affects the decomposition from ca. $220^{\circ} \mathrm{C}$. Nevertheless, the extrapolated onset temperature of the hemicellulose decomposition is practically the same at 0,5 and $21 \mathrm{~V} / \mathrm{V} \%$ oxygen. A group of 12 experiments, representing two grinding levels, three plant genera and four different heating programs were evaluated simultaneously by the method of least squares employing the model of independent pseudocomponents. All evaluated experiments were well described by the same set of kinetic parameters; only the parameters describing the peak area of the partial processes differed. A technique was recommended for the appropriate handling of the non-random errors in the simultaneous evaluation of experiment series.

\section{Introduction}

There is an increasing interest in the use of biomass as a source of energy and as raw materials due to environmental problems. The various sorts of thermal reactions have an important role during the utilization of biomass materials. Accordingly, a large number of papers published in the past few decades deal with slow and fast pyrolysis of various biomass samples. The thermal decomposition of the major biomass constituents (cellulose, hemicellulose and lignin) have been studied extensively. The main pyrolysis reactions have already been identified. ${ }^{1-8}$ There are three main regimes (moisture evolution, hemicellulose and cellulose decomposition) of weight loss during the slow pyrolysis of lignocellulosic materials in inert atmosphere. The decomposition of lignin spans over a wide temperature interval and is overlapped by the decomposition of the other components. In the presence of oxygen, pyrolysis reactions prevail at lower temperatures, while heterogeneous oxidation gives a well-identified mass-loss step at higher temperatures. ${ }^{9}$ The effect of the inorganic ions of the plant material on the rate of decomposition, char-yield and product distribution is also well-known. ${ }^{8,10}$ The various macromolecular constituents and inorganic ions are present in different relative ratios in different plant species and there are marked differences in different parts of a given plant, too. ${ }^{11}$ 
Accordingly, different behavior can be expected from different species or samples from the same species of different age, region or climate.

The reaction kinetic evaluation of slow pyrolysis experiments has also been the aim of a large number of publications. Usually the mass loss or mass loss rate is described by models assuming biomass as sum of its constituents or sum of pseudocomponents. ${ }^{10,12-23}$

In the present paper, we study the thermal behavior of young shoots obtained from a short-rotation experimental energy plantation in Hungary. The cultivation of fast growing species is considered as a viable source for energy. Several papers deal with short rotation forest biomass. ${ }^{24-28}$ However, we are unaware of publications on a detailed thermogravimetric - reaction kinetic analysis of the biomass produced in that way. The aim of the present work is to compare and characterize various biomass samples by studying their behavior at moderate heating rates in inert gas as well as in the presence of oxygen. The aims of the reaction kinetic modeling of the experiments in inert atmosphere were (i) to describe quantitatively the observed similarities; (ii) to provide models for the thermal conversion of these materials at relatively slow heating programs; (iii) and to aid the development of similar models on other biomass materials. The results may serve as kinetic components for the building of advanced future models of biomass conversion at medium temperatures. Besides, the work is hoped to contribute to the development of this type of investigations, so that TGA, a relatively simple and low priced technique, could provide reliable quantitative information on the pyrolysis processes.

\section{Experimental}

Samples. The samples were obtained from a short rotation energy plantation in Hungary. The questions of plantation management are described in details elsewhere. ${ }^{25}$ The list of the samples, their main characteristics and chemical composition can be found in Tables 1 and 2. Nine samples were taken from young shoots of poplar clones (Populus $\times$ euramericana and Populus $\times$ interamericana), black locust (Robinia pseudoacacia), and willow (Salix alba). One of the poplar samples, denoted by IP, was obtained from piles stored under industrial conditions for eight months. From a botanical point 
of view, poplar and willow are the genera of the same plant family (Salicaceae), while black locust belongs to another family (Fabaceae). For comparison, two herbaceous samples (Miscanthus sinensis) grown in the same plantation were also studied.

Prior to analysis all the samples were milled using $1 \mathrm{~mm}$ and $120 \mu \mathrm{m}$ sieves. The amounts of ethanol extractives, Klason-lignin and ash, listed in Table 2, were determined using ASTM standards E1690-01, E1721-01 and E1755-01, respectively.

Table 1. List of the Samples ${ }^{a}$

\begin{tabular}{cll}
\hline $\begin{array}{l}\text { Abbre- } \\
\text { viation }\end{array}$ & Name & Description \\
\hline IP & $\begin{array}{l}\text { Industrial sample of poplar" } \\
\text { "Pannonia" }\end{array}$ & Stored for 8 months \\
P1 & Poplara "Pannonia" & \\
P2 & Poplar "Kopeczky" & $3-5$ years old shoots \\
P3 & Poplar "Koltay" & $3-5$ years old shoots \\
P4 & Poplarc "Raspalje" & $3-5$ years old shoots \\
P5 & Poplarc "Unal" & $3-5$ years old shoots \\
R1 & Black locust (Robinia pseudoacacia) & One-year-old shoots \\
R2 & Black locust (Robinia pseudoacacia) & $3-5$ years old shoots \\
W & Willow (Salix alba) & One-year-old shoots \\
M1 & Miscanthus sinensis & - \\
M2 & Miscanthus sinensis & A cultivar obtained \\
& & by micropropagation
\end{tabular}

b.Sample taken from a 2 meter high heap of woodchips that was stored open-air under a covering roof

c Populus $\times$ interamericana

Table 2. Analytical Data of Five Selected Samples on a Dry Basis

\begin{tabular}{lccc}
\hline Sample & Klason lignin & $\begin{array}{c}\text { Ethanol } \\
\text { extractives } \\
(\%)\end{array}$ & Ash content \\
& $(\%)$ & 5.5 & $(\%)$ \\
\hline IP & 28 & na & 2.8 \\
P1 & 25 & 8.2 & 1.9 \\
R1 & 21 & 7.3 & 2.1 \\
R2 & 22 & 9.5 & 1.6 \\
W & 22 & & 1.6
\end{tabular}

Experiments. A computerized Perkin-Elmer TGS-2 thermobalance was employed in a gas flow of $140 \mathrm{ml} / \mathrm{min}$. The inert gas was high purity argon. For the oxidative measurements 5 and $21 \mathrm{~V} / \mathrm{V} \%$ oxygen-argon mixtures were used. The usual heating rate was $20^{\circ} \mathrm{C} / \mathrm{min}$. For the kinetic studies linear 
and stepwise heating programs were used, as shown in Figure 1. In inert atmosphere samples of $1-4$ mg were spread evenly in a sample holder of $\varnothing 6 \mathrm{~mm}$ to minimize the effects of heat and mass transfer limitations. The sample size was much lower $(0.2-0.4 \mathrm{mg})$ in the presence of oxygen than in argon gas flow due to the high reaction heat of the combustion processes. Since the reaction rate is roughly proportional to the heating rate in the regime of kinetic control, the heat flux of our $20^{\circ} \mathrm{C} / \mathrm{min}$ oxidative experiments is comparable to that of the $5^{\circ} \mathrm{C} / \mathrm{min}$ experiments with $1-1.5 \mathrm{mg}$ sample mass of Seneca et al. ${ }^{9}$ in air. Other authors employed 3 and $10 \mathrm{mg}$ sample masses in air at $10-12^{\circ} \mathrm{C} / \mathrm{min} .{ }^{29,30}$ Under such circumstances we have observed the combustion of the samples exhibiting sharp, tall DTG peaks at lower temperatures than the corresponding DTG peaks of the low sample mass experiments. The buoyancy effect in the low sample mass experiments was corrected by subtracting the TG signal of similar experiments with empty sample holders. We observed a good reproducibility at $0.2-0.4 \mathrm{mg}$ sample masses, too, as shown in Figure 2.

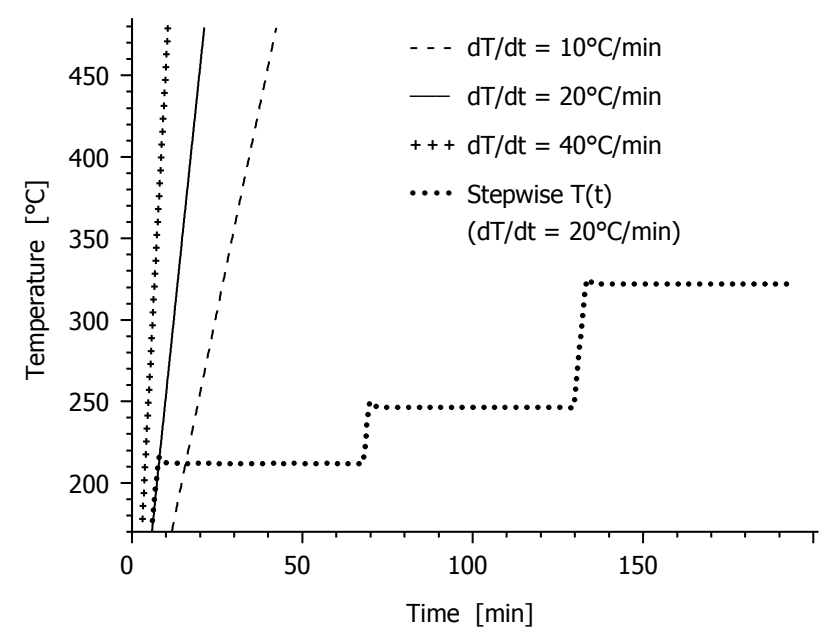

Figure 1. Heating programs for the kinetic studies. 


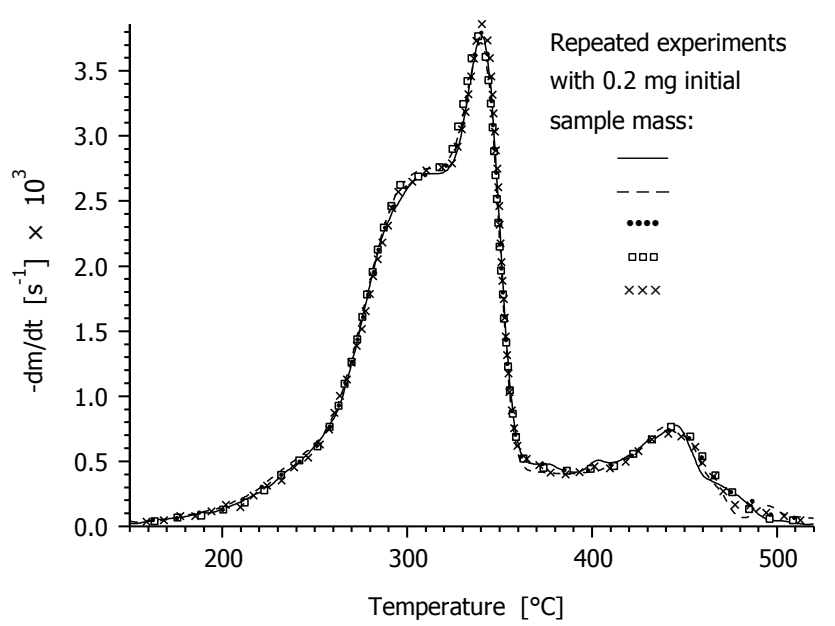

Figure 2. Repeated experiments at the lowest initial sample mass of this study, $0.2 \mathrm{mg}$, in argon gas containing $21 \mathrm{~V} / \mathrm{V} \%$ oxygen. Sample: black locust (R1). Conditions: heating rate: $20^{\circ} \mathrm{C} / \mathrm{min}$, particle size: $\leq 120 \mu \mathrm{m}$. (In all figures, $m$ denotes the normalized sample mass.)

Calculations. FORTAN 90 and C++ programs developed by one of the authors ${ }^{12,31}$ were modified according to the requirements of the present work. More emphasis was placed on the reliability of the iterations than on the computational speed. The differential equations of the models were solved by an adaptive stepwise Runge Kutta method. ${ }^{32}$ High relative precision $\left(10^{-10}\right)$ was employed. The least squares parameters were determined by the simplex direct search method ${ }^{32}$, which works reasonably on irregular surfaces, too. Each minimization was repeatedly restarted from the optimum found in the previous run of the simplex algorithm until no further improvement was achieved, as described by Press et al. ${ }^{32}$

\section{Results and Discussion}

Characterization of the experiments. Grønli et al. selected ten well-defined points for the characterization of a thermogravimetric experiment of a biomass sample. ${ }^{21}$ In the present work a subset of these quantities will be used, as shown in Figure 3 and listed below:

- $T_{\text {hc.onset }}$ is the extrapolated onset temperature calculated from the partial peak that results from the decomposition of the hemicellulose component; 
- $\quad(-d m / d t)_{\text {peak }}$ and $T_{\text {peak }}$ are the overall maximum of the mass loss rate normalized by the initial sample mass, and the corresponding temperature, respectively. $(-d m / d t)_{\text {peak }}$ and $T_{\text {peak }}$ are characteristic of the decomposition of the cellulose component;

- $T_{\text {offset }}$ is the extrapolated offset temperature of the $-d m / d t$ curves. This value describes the end of the cellulose decomposition.

- $m_{500^{\circ} \mathrm{C}}$ is the char yield at $500^{\circ} \mathrm{C}$.

The reproducibility of the above quantities was determined at a $20^{\circ} \mathrm{C} / \mathrm{min}$ heating rate. In the case of the $0.2 \mathrm{mg}$ oxidative experiments shown in Figure 2 , the standard deviation of $T_{h c . o n s e t}, T_{\text {peak }}, T_{\text {offset }}$, $(-d m / d t)_{\text {peak }}$ and $m_{500^{\circ} \mathrm{C}}$ were $1.2^{\circ} \mathrm{C}, 0.8^{\circ} \mathrm{C}, 0.5^{\circ} \mathrm{C}, 5 \times 10^{-5} \mathrm{~s}^{-1}$ and 0.004 , respectively. Another series, carried out in inert atmosphere with $4 \mathrm{mg}$ initial sample mass resulted in standard deviations of $1.2^{\circ} \mathrm{C}$, $0.7^{\circ} \mathrm{C}, 0.7^{\circ} \mathrm{C}, 3 \times 10^{-5} \mathrm{~s}^{-1}$ and 0.002 , respectively.

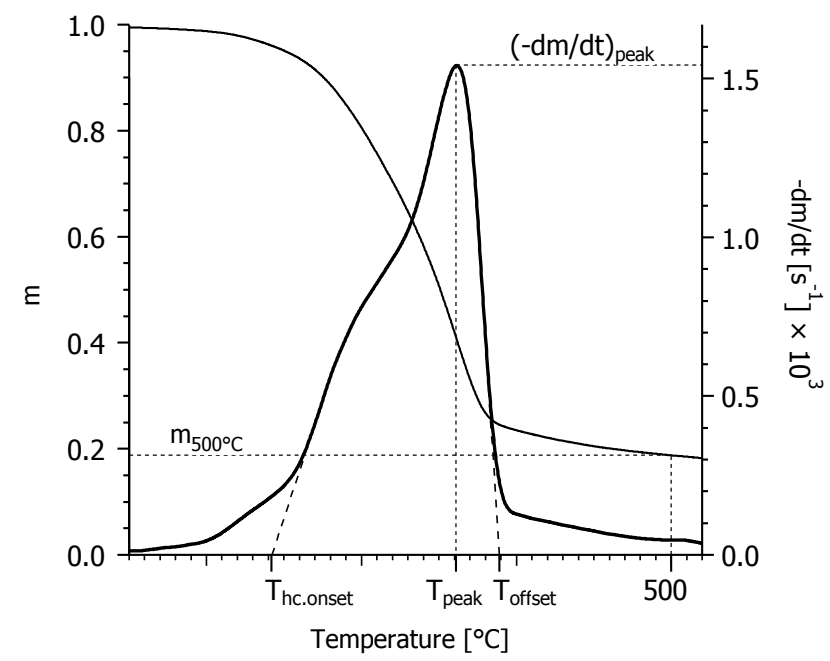

Figure 3. Definition of the characteristics of the thermogravimetric curves: TG and DTG curves of the finely ground willow sample at a $10^{\circ} \mathrm{C} / \mathrm{min}$ heating rate in inert atmosphere.

Effect of Particle Size. Investigations at well-defined temperature programs require the grinding of the samples, since one cannot ensure homogeneous sample temperatures inside large particles. We compared the behavior of differently ground samples in Figure 4 and Table 3. The difference between the average particle sizes was roughly eightfold $(\leq 1 \mathrm{~mm}$ vs. $\leq 120 \mu \mathrm{m})$. The finer grinding resulted in 
higher peak maxima; the average difference between the $(-d m / d t)_{\text {peak }}$ values is $9 \%$. There was a ca. $9 \%$ decrease in the corresponding char yields, indicating that the diffusion of the volatiles through larger samples yields more char owing to secondary cracking. ${ }^{33}$ The $T_{\text {offset }}$ values are lower at the finer grinding by an average of $5^{\circ} \mathrm{C}$ reflecting sharper cellulose peaks. The $T_{\text {peak }}$ values did not exhibit a systematic change, while the average difference between the $T_{h c . o f f s e t}$ values was only $1^{\circ} \mathrm{C}$. The above values indicate that only samples of the same particle size should be compared in relation to the thermal characteristics listed before. The visual inspection of the whole DTG curves, as shown in Figure 4 infers that the overall thermal behavior of the differently ground samples is very similar.

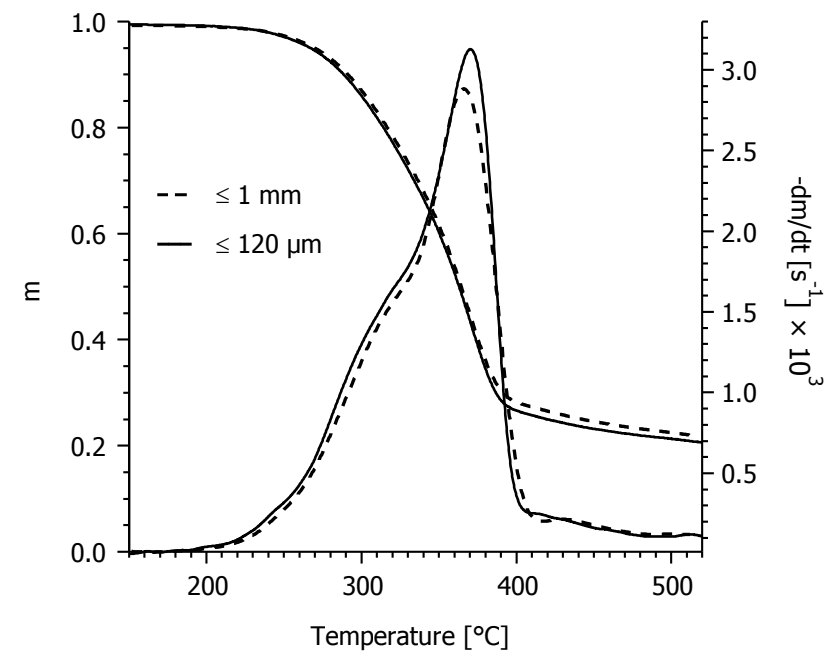

Figure 4. Effect of particle size on the thermal behavior of poplar sample IP in inert atmosphere, at a heating rate of $20^{\circ} \mathrm{C} / \mathrm{min}$.

Table 3. Effect of Particle Size in Inert Atmosphere, at $20^{\circ} \mathrm{C} / \mathrm{min}$

\begin{tabular}{llccccc}
\hline Sample & $\begin{array}{l}\text { Particle } \\
\text { size }\end{array}$ & $\begin{array}{c}\mathrm{T}_{\text {hc.onset }} \\
\left({ }^{\circ} \mathrm{C}\right)\end{array}$ & $\begin{array}{c}\mathrm{T}_{\text {peak }} \\
\left({ }^{\circ} \mathrm{C}\right)\end{array}$ & $\begin{array}{c}(-\mathrm{dm} / \mathrm{dt})_{\text {peak }} \\
\left(\mathrm{s}^{-1}\right) \times 10^{3}\end{array}$ & $\begin{array}{c}\mathrm{T}_{\text {offset }} \\
\left({ }^{\circ} \mathrm{C}\right)\end{array}$ & $\mathrm{m}_{500}{ }^{\circ} \mathrm{C}$ \\
\hline IP & $\leq 1 \mathrm{~mm}$ & 248 & 366 & 2.87 & 403 & 0.23 \\
& $\leq 120 \mu \mathrm{m}$ & 247 & 370 & 3.13 & 398 & 0.21 \\
$\mathbf{P 1}$ & $\leq 1 \mathrm{~mm}$ & 250 & 374 & 2.87 & 412 & 0.19 \\
& $\leq 120 \mu \mathrm{m}$ & 249 & 378 & 3.13 & 404 & 0.18 \\
$\mathbf{R 1}$ & $\leq 1 \mathrm{~mm}$ & 247 & 372 & 2.65 & 404 & 0.22 \\
& $\leq 120 \mu \mathrm{m}$ & 246 & 365 & 2.94 & 397 & 0.18 \\
$\mathbf{W}$ & $\leq 1 \mathrm{~mm}$ & 251 & 377 & 2.85 & 406 & 0.21 \\
& $\leq 120 \mu \mathrm{m}$ & 248 & 372 & 3.00 & 401 & 0.18
\end{tabular}

Thermal Behavior of the Samples. In a recent paper, Grønli et al. ${ }^{21}$ reported considerable differences on the thermal behavior of different species of hardwood. In the present work, however, 
wood samples from different plant genera and families exhibited surprisingly similar characteristics, as shown in Table 4 and Figure 5. Let us start the survey by inspecting the scattering of the experimental characteristics within the poplar clones. Table 4 contains separate averaging and standard deviation data for samples P1 - P5. There is a moderate scattering that may be due to small differences in the amount of bark, inorganic ions, etc. in the different samples. The cellulose content of the industrial poplar sample (IP), which was stored in open air, decomposes at ca. $6^{\circ} \mathrm{C}$ lower temperatures than in case of the other poplar samples. (See the $T_{\text {peak }}$ and $T_{\text {offset }}$ values in Table 4.) It is interesting to note that the data of the black locust and willow samples only slightly differ from that of the poplar clones. (See Figure 5B.) There is a significant difference between the peak temperatures of the two black locust samples $\left(365\right.$ vs. $\left.372^{\circ} \mathrm{C}\right)$. This may be due to the age difference between the corresponding shoots, which strongly affects the ratios of bark, heart- and sapwood in the samples. ${ }^{27}$ (Note that R1 and R2 were taken from one year old and 3-5 years old shoots, respectively.) The Miscanthus samples behave similarly to the wood samples except that their $\mathrm{T}_{\mathrm{hc} \text {.onset }}$ values are higher by ca. $20^{\circ} \mathrm{C}$ than the mean $\mathrm{T}_{\text {hc.onset }}$ of the wood species. This may be due to the chemically different hemicellulose compositions in the hardwoods and in the herbaceous plants.

Table 4. Characteristics of the Thermogravimetric Curves in Inert Atmosphere at Heating Rate of $20^{\circ} \mathrm{C} / \mathrm{min}$ and Particle Size $\leq 120 \mu \mathrm{m}$

\begin{tabular}{lccccc}
\hline Sample & $\begin{array}{c}\mathrm{T}_{\text {hc.start }} \\
\left({ }^{\circ} \mathrm{C}\right)\end{array}$ & $\begin{array}{c}\mathrm{T}_{\text {peak }} \\
\left({ }^{\circ} \mathrm{C}\right)\end{array}$ & $\begin{array}{c}(-\mathrm{dm} / \mathrm{dt})_{\text {peak }} \\
\left(\mathrm{s}^{-1}\right) \times 10^{3}\end{array}$ & $\begin{array}{c}\mathrm{T}_{\text {offset }} \\
\left({ }^{\circ} \mathrm{C}\right)\end{array}$ & $\mathrm{m}_{500^{\circ} \mathrm{C}}$ \\
\hline $\mathrm{IP}$ & 247 & 370 & 3.13 & 398 & 0.21 \\
$\mathrm{P} 1$ & 249 & 378 & 3.13 & 404 & 0.18 \\
$\mathrm{P} 2$ & 247 & 376 & 2.97 & 405 & 0.18 \\
$\mathrm{P} 3$ & 247 & 374 & 2.87 & 403 & 0.20 \\
$\mathrm{P} 4$ & 249 & 378 & 3.27 & 404 & 0.17 \\
$\mathrm{P} 5$ & 251 & 376 & 3.07 & 404 & 0.17 \\
$\mathrm{R} 1$ & 246 & 365 & 2.94 & 397 & 0.18 \\
$\mathrm{R} 2$ & 249 & 372 & 3.07 & 402 & 0.16 \\
$\mathrm{~W}$ & 248 & 372 & 3.00 & 401 & 0.18 \\
M1 & 267 & 372 & 3.17 & 405 & 0.22 \\
M2 & 269 & 372 & 3.19 & 402 & 0.23 \\
Means and standard deviations: & & & \\
Poplars P1-P5 & $249 \pm 2$ & $376 \pm 2$ & $3.06 \pm 0.15$ & $404 \pm 1$ & $0.18 \pm 0.01$ \\
Woods & $248 \pm 2$ & $373 \pm 4$ & $3.05 \pm 0.12$ & $402 \pm 3$ & $0.18 \pm 0.02$ \\
All samples & - & $373 \pm 4$ & $3.07 \pm 0.12$ & $402 \pm 3$ & $0.19 \pm 0.02$
\end{tabular}




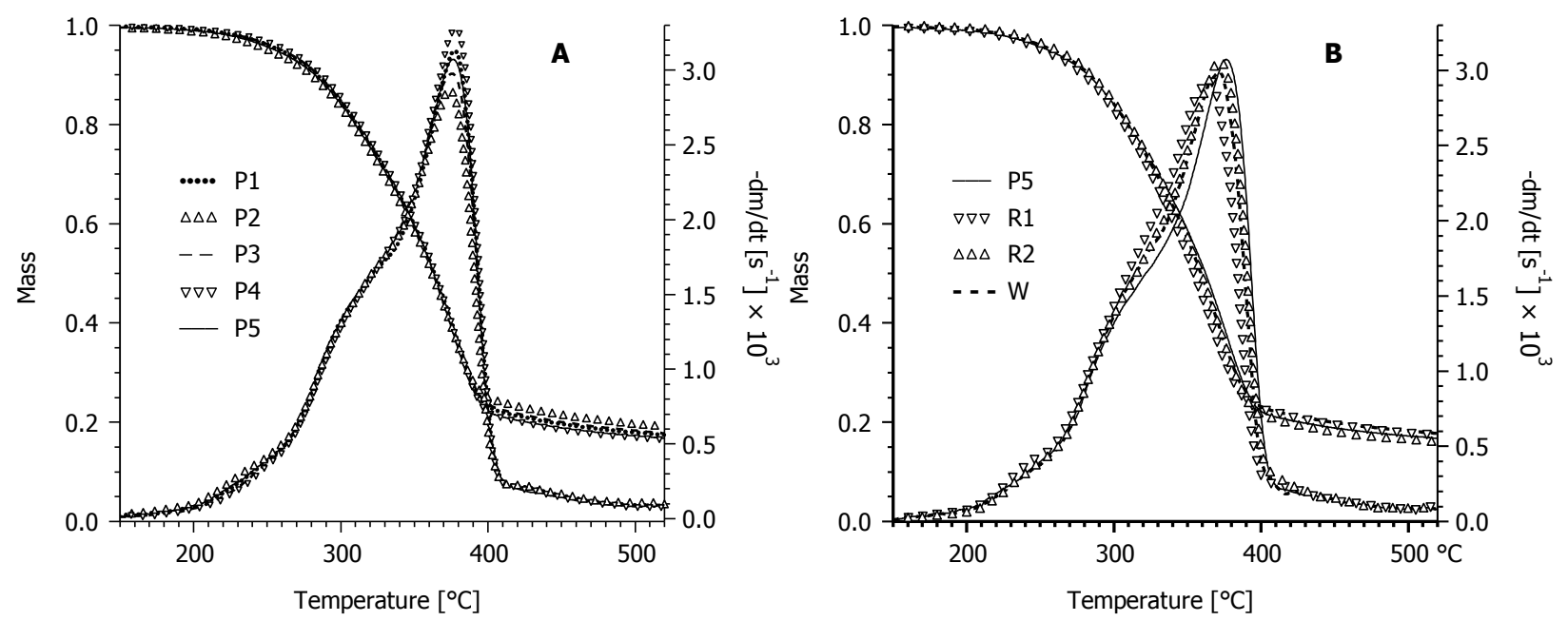

Figure 5. Comparison of the TG and DTG curves of poplar clones (a); and poplar, black locust and willow samples (b). Conditions: argon atmosphere, particle size $\leq 120 \mu \mathrm{m}$, heating rate: $20^{\circ} \mathrm{C} / \mathrm{min}$.

The role of oxygen. Figure 6 shows that the presence of oxygen in the ambient gas starts to affect the decomposition of the wood samples at temperatures as low as $220^{\circ} \mathrm{C}$. Nevertheless, the extrapolated onset temperature of the hemicellulose decomposition, listed in Table 5, is practically the same at 0,5 and $21 \mathrm{~V} / \mathrm{V} \%$ oxygen. Accordingly, it can be concluded that the start of the hemicellulose decomposition, around $248^{\circ} \mathrm{C}$, is not influenced by the presence of oxygen. On the other hand, the characteristic temperatures of the cellulose decomposition, $T_{\text {peak }}$ and $T_{\text {offset }}$, exhibit a marked dependence on the oxygen concentration, as shown in Table 6 . The peak arising between $400-500^{\circ} \mathrm{C}$ is due to the burn-off of the char formed. Bilbao et al. ${ }^{29}$ studied the influence of oxygen concentration in TG experiments using pine sawdust samples. Their results showed a considerably stronger sharpening of the cellulose peak in air than our results in this case. The ratio of the DTG peak height, $(-d m / d t)_{\text {peak }}$, at $21 \%$ and $0 \% \mathrm{O}_{2}$ was around 1.8 in the paper of Bilbao et al. This value is only around $1.2-1.4$ in the present work. It is possible that this difference appears due to the differences of the species studied. However, the higher sample mass employed by Bilbao et al. may also be responsible for the observed differences, as it was described in the Experimental.

The thermal behavior of four wood species of the present work in $21 \% \mathrm{O}_{2}$ is compared in Figure 7. The same samples are shown as in Figure 5B in argon atmosphere, but the sample mass and heating rate 
is decreased here to $0.4 \mathrm{mg}$ and $10^{\circ} \mathrm{C} / \mathrm{min}$, respectively, to exclude the self-heating problems due to the high reaction heat. Figure 7 shows an almost perfect agreement in the peak temperatures as well as in the ascending and descending sections of the DTG curves until ca. $420^{\circ} \mathrm{C}$, while the heights of the partial peaks differ. Small differences can be observed in the char burn-off peak, around $460^{\circ} \mathrm{C}$.

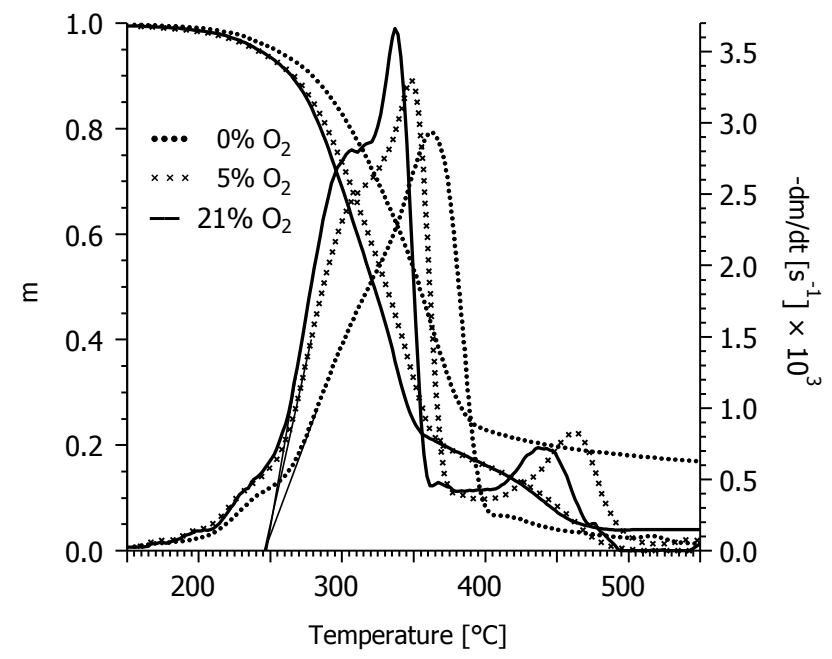

Figure 6. TG and DTG curves of sample R2 in argon flushing gas with different oxygen concentration at heating rate of $20^{\circ} \mathrm{C} / \mathrm{min}$ and particle size $\leq 120 \mu \mathrm{m}$. Thin solid lines indicate the extrapolated onset temperature of the hemicellulose decomposition.

Table 5. The Effect of Oxygen Concentration on the Thermal Behavior at Heating Rate of $20^{\circ} \mathrm{C} / \mathrm{min}$ and Particle Size $\leq 120 \mu \mathrm{m}$

\begin{tabular}{lccccc}
\hline Sample & $\begin{array}{l}\text { Oxygen } \\
\text { concentration } \\
(\mathrm{V} / \mathrm{V} \%)\end{array}$ & $\begin{array}{c}\mathrm{T}_{\text {hc.onset }} \\
\left({ }^{\circ} \mathrm{C}\right)\end{array}$ & $\begin{array}{c}\mathrm{T}_{\text {peak }} \\
\left({ }^{\circ} \mathrm{C}\right)\end{array}$ & $\begin{array}{c}(-\mathrm{dm} / \mathrm{dt})_{\text {peak }} \\
\times 10^{3}\end{array}$ & $\begin{array}{c}\mathrm{T}_{\text {offset }} \\
\left(\mathrm{s}^{-1}\right)\end{array}$ \\
\hline IP & 0 & 247 & 370 & 3.13 & 398 \\
IP & 5 & 248 & 348 & 3.57 & 370 \\
IP & 21 & 247 & 337 & 3.92 & 359 \\
R1 & 0 & 246 & 365 & 2.94 & 397 \\
R1 & 5 & 246 & 347 & 3.21 & 373 \\
R1 & 21 & 247 & 335 & 3.43 & 362 \\
W & 0 & 248 & 372 & 2.99 & 401 \\
W & 5 & 248 & 350 & 3.42 & 372 \\
W & 21 & 249 & 339 & 4.25 & 357
\end{tabular}


Table 6. Change of Characteristic Temperature Values by Increasing Oxygen Concentrationa

\begin{tabular}{lllllll}
\hline Sample & \multicolumn{2}{c}{ Differences between 0 and $5 \% \mathrm{O}_{2}$} & \multicolumn{3}{c}{ Differences between 5 and $21 \% \mathrm{O}_{2}$} \\
& $\Delta \mathrm{T}_{\text {hc.onset }}$ & $\Delta \mathrm{T}_{\text {peak }}$ & $\Delta \mathrm{T}_{\text {offset }}$ & $\Delta \mathrm{T}_{\text {hc.onset }}$ & $\Delta \mathrm{T}_{\text {peak }}$ & $\Delta \mathrm{T}_{\text {offset }}$ \\
\hline IP & -1 & 22 & 28 & -1 & 11 & 11 \\
R1 & 0 & 18 & 24 & -1 & 12 & 11 \\
W & 0 & 22 & 29 & -1 & 11 & 15
\end{tabular}

${ }^{\text {a }}$ Differences are formed from the data of Table 5.

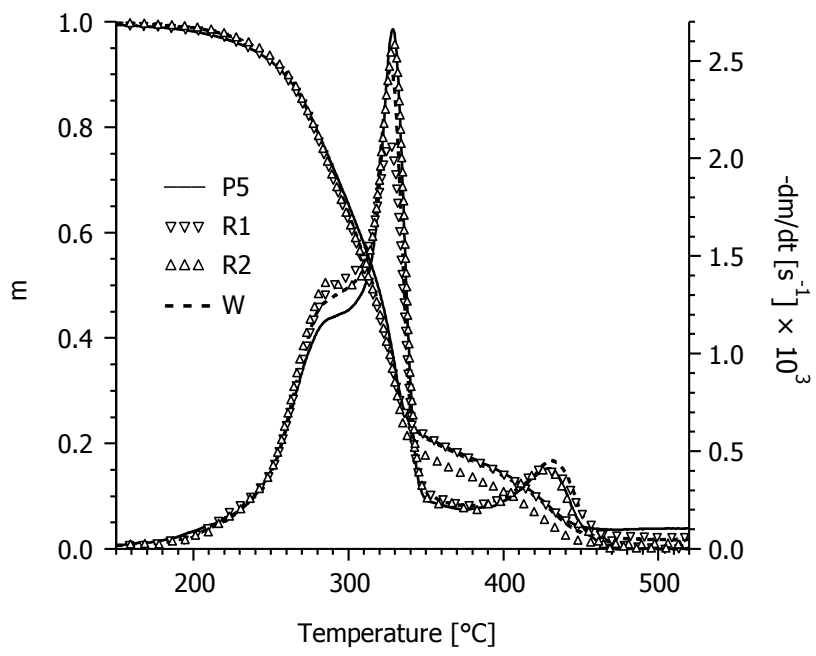

Figure 7. TG and DTG curves of wood samples in argon gas containing $21 \mathrm{~V} / \mathrm{V} \%$ oxygen. Conditions: heating rate: $10^{\circ} \mathrm{C} / \mathrm{min}$, particle size: $\leq 120 \mu \mathrm{m}$.

\section{Kinetic Modeling of Thermal Decomposition in Inert Ambient}

The Model of Pseudocomponents. The non-isothermal thermogravimetric experiments of the biomass samples result in DTG curves consisting of partially overlapping peaks. A mathematical model is needed for the deconvolution of the observed DTG curves. The usual way is to assume parallel, independent reactions. ${ }^{10,12-23}$ Each of these reactions is supposed to have its own pool of reacting groups, i.e. the volatiles are assumed to be formed from pseudocomponents. For each pseudocomponent a conversion (reacted fraction), $\alpha_{j}$ and a reaction rate, $d \alpha_{j} / d t$ are defined. (See the "Nomenclature" section for symbols and subscripts.) The overall reaction rate of the sample is a linear combination of the reaction rates of the partial reactions, $d \alpha_{j} / d t$ :

$$
-d m^{\text {calc }} / d t=\sum_{j=1}^{M} c_{j} d \alpha_{j} / d t
$$


Here $M$ is the number of the pseudocomponents and $c_{j}$ is the amount of volatiles formed from the $j$ th pseudocomponent. Each $\alpha_{\mathrm{j}}$ reacted fraction has its own kinetic equation with its own parameters:

$$
d \alpha_{j} / d t=A_{j} \exp \left(-E_{j} / R T\right)\left(1-\alpha_{j}\right)^{n_{j}}
$$

where $A_{j}$ is the preexponential factor, $E_{j}$ is the apparent activation energy, and $n_{j}$ is a parameter expressing the approximate dependence of the reactivity on the advance of the reaction. In the case of a linear heating program, $n_{j}$ influences the shape of the corresponding simulated peak.

Evaluation of Different Species with the Same Kinetic Parameters. It was shown in a recent work that hardwood and softwood samples belonging to different genera can be described by a model of type eq 1 using first order kinetic equations with the same set of activation energy values. ${ }^{21}$ In this way the shape and width of the partial curves are identical, while the positions and areas of the peaks, associated with parameters $A_{j}$ and $c_{j}$, vary from species to species. In the present work, however, the wood samples revealed a thermal behavior highly similar to each other. Accordingly, one can attempt a modeling of the corresponding DTG curves with partial peaks whose shapes, widths and positions are the same for all species evaluated, and only the peak areas vary among the samples. Denoting the parameters by vectors, we shall look for common $\underline{E}, \underline{A}$ and $\underline{n}$ vectors for the whole set of experiments evaluated, while the $\underline{c}$ vectors will vary from species to species. This approach assumes that the pesudocomponents decompose in the same way in the different samples, but their contribution to the overall mass loss may be different. Note that a $c$ parameter can be interpreted as the product of two factors: the concentration of the corresponding pseudocomponent and the amount of volatiles formed from the given pseudocomponent.

Samples and Temperature Programs for the Kinetic Evaluation. We aimed at establishing models that describe the behavior of the samples in a wide range of experimental conditions. Accordingly, four different temperature programs were employed for each samples evaluated, as shown in Figure 1. For computational reasons, the number of experiments evaluated simultaneously was limited to 12 , hence three samples, IP, R2 and W, were selected for the evaluation. Since the model was 
hoped to describe the whole range of observations, the roughly ground $(<1 \mathrm{~mm})$ sample was used from IP. In this way, two grinding levels and three plant genera of two families were represented in the kinetic evaluation.

Evaluation by the Method of Least Squares. The unknown parameters of the models were determined by the simultaneous evaluation of 12 experiments:

$$
S=\sum_{s=1}^{3} \sum_{p=1}^{4} \sum_{i=1}^{N_{s, p}}\left[\left(\frac{d m}{d t}\right)_{s, p}^{o b s}\left(t_{i}\right)-\left(\frac{d m}{d t}\right)_{s, p}^{c a l c}\left(t_{i}\right)\right]^{2} / N_{s, p} / h_{s, p}^{2}
$$

Here subscripts $s$ and $p$ indicate the species and the heating programs, respectively. $t_{i}$ denotes the time values in which digitized $(d m / d t)^{o b s}$ values were taken, and $N_{s, p}$ is the number of the $t_{i}$ points in a given experiment. $h_{s, p}$ denotes the heights of the evaluated curves $\left[h_{s, p}=\max (-d m / d t)_{s, p}^{o b s}\right]$. The division by $h_{s, p}$ serves for normalization. For each experimental curve, the obtained fit was characterized by the following quantity:

$$
f i t(\%)=100\left\{\sum_{i=1}^{N_{\mathrm{s}, \mathrm{p}}}\left[\left(\frac{d m}{d t}\right)_{s, p}^{o b s}\left(t_{i}\right)-\left(\frac{d m}{d t}\right)_{s, p}^{c a l c}\left(t_{i}\right)\right]^{2} / N_{s, p}\right\}^{0.5} / h_{s, p}
$$

Handling the Uncertainty of the Yield of Solid Residue. The method of least squares can only deal with the random, independent part of the experimental errors. The thermal investigation methods and the description of the experimental data by simplified models inevitably involve such experimental and model errors that appear like the distortion of the whole curves. Their proper handling is a crucial point of the simultaneous evaluation of series of experiments. In the model outlined above, the amount of solid residue of species $s$ converges to an $m_{s}(\infty)$ value at $t=\infty$ :

$$
m_{s}(\infty)=1-\sum_{j=1}^{M} c_{s, j}
$$


In reality, however, the amount of solid residue shows a slight dependence on the heating rate due to disregarded side reactions, and it is also disturbed by experimental errors. ${ }^{34}$ We introduced quantities $\delta m_{s, p}(\infty)$ to describe these uncertainties: $m_{s, p}^{\text {calc }}(t)$ converges to an $m_{s}(\infty)+\delta m_{s, p}(\infty)$ value instead of $m_{s}(\infty)$. The $\delta m_{s, p}(\infty)$ values were determined together with the other unknown parameters during the least squares evaluation. The experiments at heating program 1 (i.e. the $10^{\circ} \mathrm{C} / \mathrm{min}$ experiments) were chosen as reference points, i.e. $\delta m(\infty)$ was considered zero in case of $10{ }^{\circ} \mathrm{C} / \mathrm{min}$ heating rate. In this way the $\delta m_{s, p}(\infty)$ values express the difference between the $m_{s}(\infty)$ values of heating program $p$ and 1 . There is no sufficient information on the contribution of the various pseudocomponents, or temperature domains to the slight variation of the final residue. Accordingly, we distributed the $\delta m_{s, p}(\infty)$ uncertainties among all pseudocomponents, as follows. Each experiment has its own set of $c$ coefficients, denoted by vectors $\underline{c}_{s, p}$. The $\underline{c}_{s, p}$ vectors of a given species $s$ differ by factors $f_{s, p} \approx 1$ from each other. Since $\delta m_{s, 1}(\infty)=0$ by definition (as described above), we have

$$
\underline{c}_{s, p}=f_{s, p} \underline{c}_{s, 1} \quad(p=2,3,4)
$$

From eq 5 we get the relationship between factors $f_{s, p}$ and the uncertainties of the $m_{\mathrm{s}}(\infty)$ values:

$$
f_{s, p}=1-\delta m_{s, p}(\infty) /\left[1-m_{s}(\infty)\right]
$$

Eqs 6 and 7 served for the calculation of the $\underline{c}_{s, p}$ vectors from the $\delta m_{s, p}(\infty)$ parameters during the iteration.

Handling the Uncertainty of the Sample Temperature. Another source of uncertainty rises from the deviation of the true sample temperature from the observed values. Although the magnitude of this error can be diminished by employing low sample masses and temperature calibration procedures, it cannot be completely eliminated. A recent round-robin TGA study ${ }^{34}$ showed that one of the main components of the systematic $T$ errors is a constant term that shifts a non-isothermal TG or DTG curve left or right along the $T$ axis. (This observation is valid only when the heat flux associated with the chemical reactions is low, i.e. when the sample mass is sufficiently low for the given type of reaction.) Based on this observation, we introduce the method outlined below. Let us denote the constant part of 
the systematic errors of a given experiment by $\delta T_{s, p}$. The $\delta T_{s, p}$ values can be determined together with the other unknown parameters during the least squares evaluation. Obviously, the absolute value of the mean temperature error cannot be determined by reaction kinetic modeling, only the differences from a reference experiment. Accordingly, the first $\delta T$ value, $\delta T_{1,1}$ can be chosen zero. In other words, a $\delta T_{s, p}$ parameter expresses the difference of the mean temperature errors between experiment $s, p$ and experiment 1,1 .

Controlling the Magnitude of Parameters $\delta m(\infty)$ and $\delta T$. From a mathematical point of view, the high number of unknown parameters presented a certain level of ill-definition in the model. To overcome this difficulty, available information about the magnitude of the $\delta m(\infty)$ and $\delta T$ quantities were introduced into the evaluation. The experience of the authors with the present data set as well as with other biomass samples showed that the char yield and temperature uncertainties are roughly around 0.01 and a few centigrade, respectively. Accordingly, the magnitude of the $\delta m_{s, p}(\infty)$ and $\delta T_{s, p}$ quantities were kept roughly within these limits during the evaluation. This can be achieved by adding simple "penalty" terms to objective function $S$ defined by eq 3 . The following quantity was minimized:

$$
S+\lambda_{m}\|\underline{\underline{\delta m(\infty)}}\|^{2}+\lambda_{T}\|\underline{\underline{\delta T}}\|^{2}
$$

where $\|\underline{\underline{\delta m(\infty)}}\|^{2}$ and $\|\underline{\underline{\delta T}}\|^{2}$ denotes the sum of square values of the $\delta m_{s, p}(\infty)$ and $\delta T_{s, p}$ quantities, respectively, and $\lambda_{m}$ and $\lambda_{T}$ are multipliers. Penalty functions of the above type were employed on similar quantities in earlier studies of the authors. ${ }^{35-36}$ They served as a way of regularization. ${ }^{37}$ Several test calculations showed that the results of the minimization are not sensitive to the exact choice of the multipliers of the penalty terms. In the present work, $\lambda_{m}=10^{-3}$ and $\lambda_{T}=5 \times 10^{-7}$ proved to be suitable to achieve a reliable iteration, a good fit and a moderate scattering of the $\delta m_{s, p}(\infty)$ and $\delta T_{s, p}$ quantities. The results presented below belong to these values. When the parameters minimizing eq 8 are found, the penalty terms can be removed from the objective function and the iterations can be continued without a substantial change of the resulting kinetic parameters, as outlined later in the paper. 
Model Assuming First Order Kinetics for the Partial Reactions. The partial reactions of the biomass decomposition are usually approximated by first-order reactions. ${ }^{10,12-22}$ For the description of the present data set of three samples at four heating programs, six partial peaks were necessary. Their parameters and characteristics are listed in Table 7. The variation of the $c$ parameters of a given species, described above, was very small, in the order of 0.002 , accordingly only the means of the $c$ parameters are shown for each species. The peak temperatures and peak widths belonging to heating rates 10 and $20^{\circ} \mathrm{C} / \mathrm{min}$ are also listed in Table 7 to aid the identification of the corresponding processes. The partial curves and the fit between the experimental and simulated DTG curves are shown in Figures 8 and 9. Based on earlier results on lignin decomposition ${ }^{21,38,39}$, we can assume that the lignin content of the samples, decomposing in a very wide temperature domain, contributes more or less to all peaks. The first peak, around $236^{\circ} \mathrm{C}$ at $10^{\circ} \mathrm{C} / \mathrm{min}$ heating rate, is mainly the result of the decomposition of the thermally labile functional groups of the hemicellulose and various extractive materials. ${ }^{7}$ The next two peaks, around $285^{\circ} \mathrm{C}$ and $317^{\circ} \mathrm{C}$ at $10^{\circ} \mathrm{C} / \mathrm{min}$ heating rate, are dominated by the hemicellulose decomposition, while the sharp, high peaks around $356^{\circ} \mathrm{C}$ are characteristic to the cellulose pyrolysis. The $5^{\text {th }}$ peak, around $384^{\circ} \mathrm{C}$, can be attributed either to a cellulose fraction, or to lignin ${ }^{38,39}$. The $6^{\text {th }}$ peak, around $443^{\circ} \mathrm{C}$, belongs to lignin thermolysis. Note that the wood components are chemically heterogeneous materials. In studies based only on linear heating programs, the decomposition can frequently be approximated by three partial reactions ${ }^{10,12-23}$. However, the stepwise temperature programs employed in the present work require a more accurate description of the temperature dependence of the corresponding reaction rates. 
Table 7. Results of the Evaluation by the First-order Model

\begin{tabular}{|c|c|c|c|c|c|c|}
\hline Peak & 1 & 2 & 3 & 4 & 5 & 6 \\
\hline $\begin{array}{l}\text { Contributing } \\
\text { components }^{\mathrm{a}}\end{array}$ & $e, h c, l$ & $h c, l$ & $h c, l$ & cel & cel or $l$ & $l$ \\
\hline $\begin{array}{l}\text { Line style in } \\
\text { Figures } 8 \text { and } 9\end{array}$ & - & $x \times x$ & -- & +++ & 000 & \\
\hline $\mathrm{E} / \mathrm{kJ} \mathrm{mol}^{-1}$ & 90 & 146 & 165 & 188 & 241 & 84 \\
\hline $\log _{10}\left(\mathrm{~A} / \mathrm{s}^{-1}\right)$ & 7.1 & 11.6 & 12.6 & 13.6 & 17.5 & 3.91 \\
\hline \multicolumn{7}{|l|}{ c values $^{b}:$} \\
\hline Poplar "IP" & 0.03 & 0.11 & 0.13 & 0.41 & 0.01 & 0.08 \\
\hline Black locust " & & 0.11 & 0.17 & 0.35 & 0.10 & 0.07 \\
\hline Willow "W" & 0.05 & 0.12 & 0.16 & 0.37 & 0.05 & 0.06 \\
\hline
\end{tabular}

Peak characteristics simulated at $10^{\circ} \mathrm{C} / \mathrm{min}$ :

$\begin{array}{lcccccc}\mathrm{T}_{\text {peak }} /{ }^{\circ} \mathrm{C} & 236 & 285 & 317 & 356 & 374 & 413 \\ \mathrm{FWHM}^{\mathrm{c}} /{ }^{\circ} \mathrm{C} & 55 & 42 & 41 & 41 & 34 & 105\end{array}$

Peak characteristics simulated at $20^{\circ} \mathrm{C} / \mathrm{min}$ :

$\begin{array}{lcccccc}\mathrm{T}_{\text {peak }} /{ }^{\circ} \mathrm{C} & 252 & 297 & 328 & 368 & 384 & 443 \\ \mathrm{FWHM}^{\mathrm{b}} /{ }^{\circ} \mathrm{C} & 58 & 43 & 43 & 43 & 36 & 114\end{array}$

${ }^{a}$ The supposed main sources of the mass loss are indicated. ( $e=$ extractives, $h c=$ hemicellulose, cel=cellulose, $l=$ lignin.)

${ }^{\mathrm{b}}$ Mean values are shown. The $c$ values of a given species vary in the different experiments by a standard deviation of 0.002 .

${ }^{\mathrm{c}}$ Full width at half maximum.
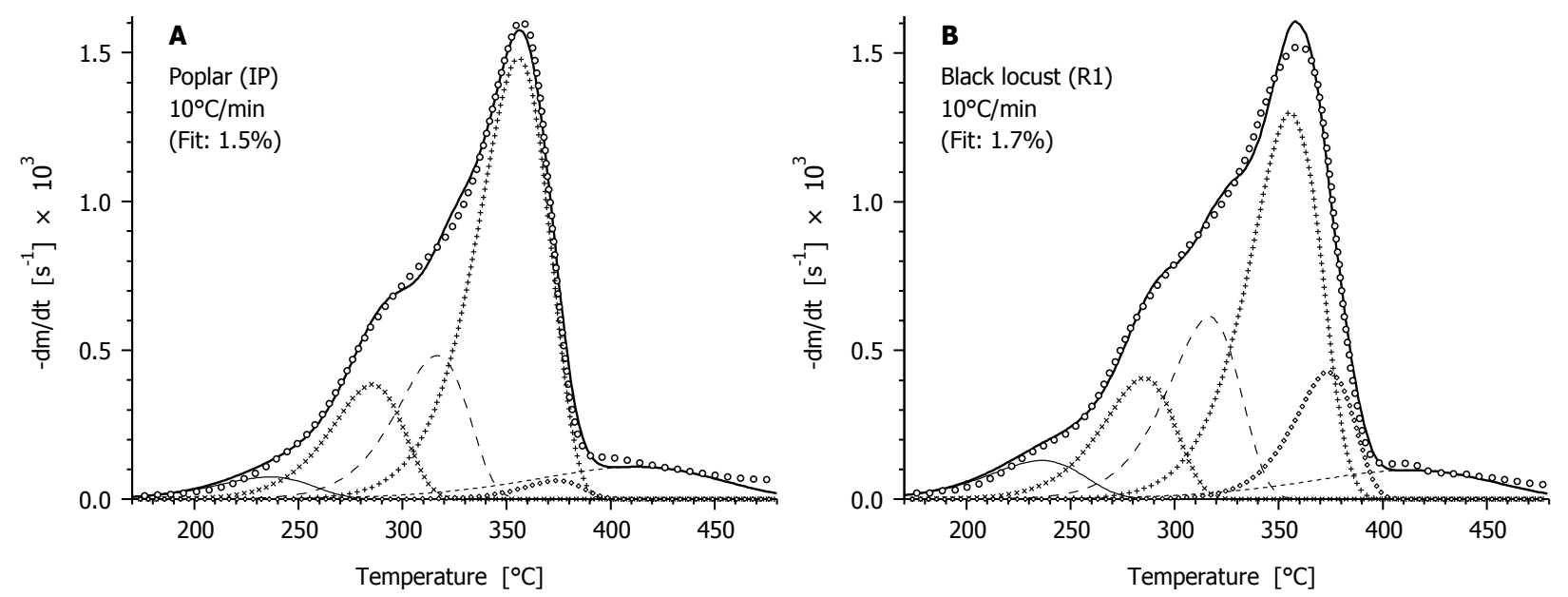


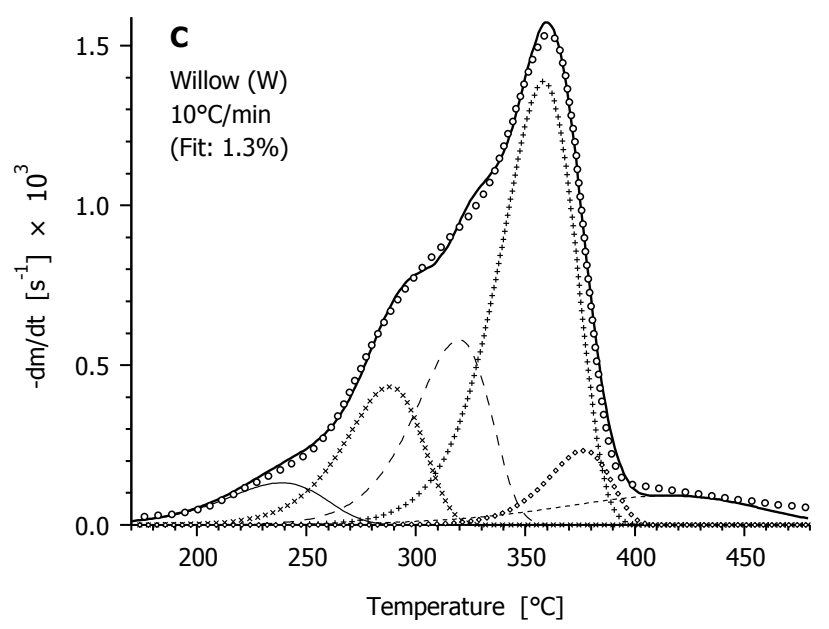

Figure 8. Comparison between the observed (o ० o) and simulated (一) DTG curves at $10^{\circ} \mathrm{C} / \mathrm{min}$ employing the first order model. Thin lines of different styles and symbols $\times,+$ and $\diamond$ denote the simulated curves of the partial reactions. (See Table 7. The peaks are numbered from left to right.)
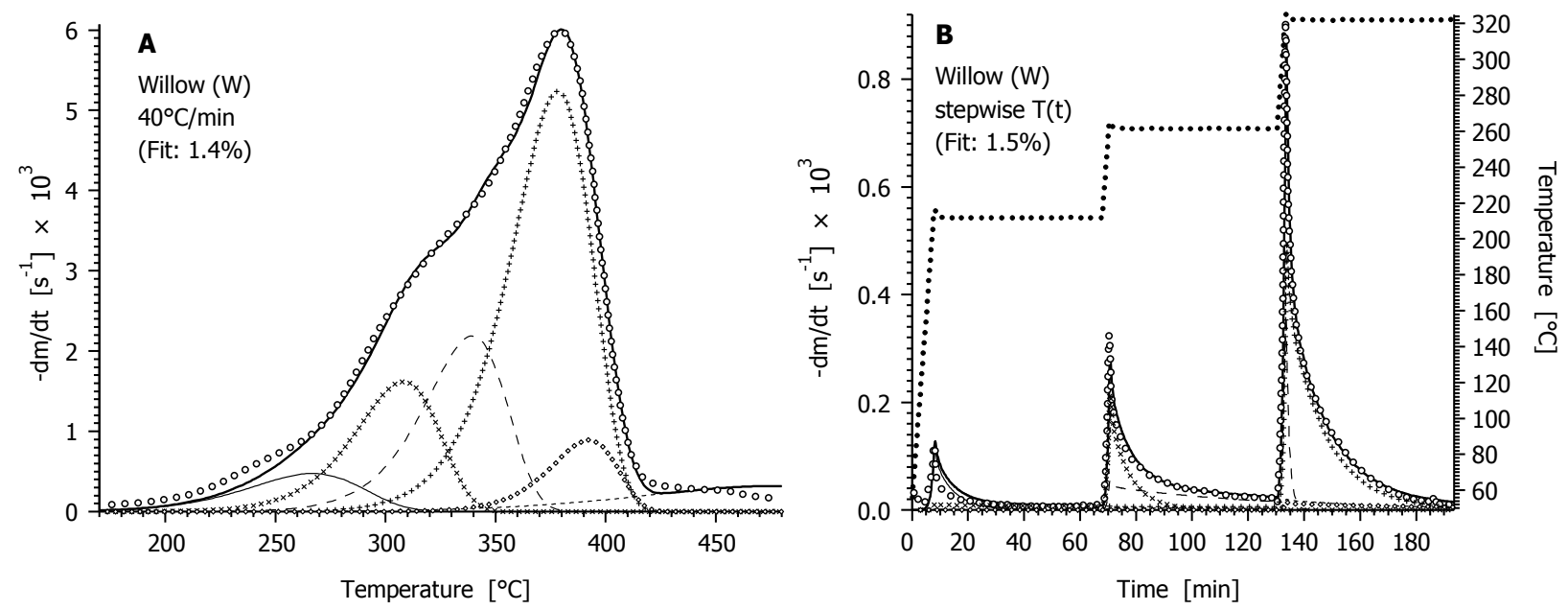

Figure 9. Comparison between the observed (o o o) and simulated (-) DTG curves at $40^{\circ} \mathrm{C} / \mathrm{min}$ (A) and at a stepwise temperature program (line $\cdots$ in panel B) employing the first order model. Thin lines of different styles and symbols $\mathrm{x},+$ and $\diamond$ denote the simulated curves of the partial reactions. (See Table 7.)

Model Assuming $\boldsymbol{n}$ th Order Kinetics for the Partial Reactions. The literature of the thermal analysis contains numerous models for heterogeneous reactions that assume reactions only on special surfaces. In case of biomass materials pyrolyzing in the kinetic regime we are unaware of physical or chemical causes that could restrict the thermal decomposition to some special surfaces. In a similar way, one cannot expect true bimolecular, second order reactions in the solid phase of pyrolyzing wood. 
Nevertheless, a parameter like $n$ in eq 2 may be helpful to describe formally the various

inhomogeneities of the main biomass components. Thus, we accomplished modeling the experiments with four partial reactions. We limited the iteration to $n \leq 2$ since higher $n$ values resulted in quite unusual peak shapes. The results are displayed in Table 8 and Figure 10. It is interesting to note that $n=1.00$ was observed for the cellulose (peak 3), in accordance with the pyrolysis kinetics of pure cellulose samples. ${ }^{40}$ The $n$ parameters of the other partial processes converged to the $\mathrm{n}=2$ limit. Test calculations showed that the fit can only slightly be improved without the $\mathrm{n} \leq 2$ conditions, while the asymmetry and the long tailing sections of the partial peaks increased, resulting in unrealistic peak shapes.

Table 8. Results of the Evaluation by the $n$ th-order model

\begin{tabular}{|c|c|c|c|c|c|}
\hline Peak & 1 & 2 & 3 & 4 & \\
\hline $\begin{array}{l}\text { Contributing } \\
\text { components }^{\mathrm{a}}\end{array}$ & $e, h c, l$ & $h c, l$ & cel & $l$ & \\
\hline $\begin{array}{l}\text { Line style in } \\
\text { Figure } 10\end{array}$ & - & -- & +++ & -- & \\
\hline $\mathrm{E} / \mathrm{kJ} \mathrm{mol}^{-1}$ & 114 & 167 & 187 & 146 & \\
\hline $\log _{10}\left(\mathrm{~A} / \mathrm{s}^{-1}\right)$ & 9.0 & 13.0 & 13.4 & 8.8 & \\
\hline $\mathrm{n}$ & 2.00 & 2.00 & 1.00 & 2.00 & \\
\hline \multicolumn{6}{|l|}{ c values ${ }^{b}$} \\
\hline Poplar "IP" & 0.08 & 0.23 & 0.40 & 0.06 & \\
\hline Black locust "R1" & 0.12 & 0.26 & 0.40 & 0.06 & \\
\hline Willow "W" & 0.12 & 0.25 & 0.39 & 0.05 & \\
\hline \multicolumn{6}{|c|}{ Peak characteristics simulated at $10^{\circ} \mathrm{C} / \mathrm{min}$ : } \\
\hline $\mathrm{T}_{\text {peak }} /{ }^{\circ} \mathrm{C}$ & 260 & 308 & 360 & 416 & \\
\hline $\mathrm{FWHM}^{\mathrm{c}} /{ }^{\circ} \mathrm{C}$ & 68 & 56 & 42 & 89 & \\
\hline \multicolumn{6}{|c|}{ Peak characteristics simulated at $20^{\circ} \mathrm{C} / \mathrm{min}$ : } \\
\hline $\mathrm{T}_{\text {peak }} /{ }^{\circ} \mathrm{C}$ & 274 & 320 & 372 & 434 & \\
\hline $\mathrm{FWHM}^{\mathrm{c}} /{ }^{\circ} \mathrm{C}$ & 72 & 58 & 43 & 93 & \\
\hline
\end{tabular}



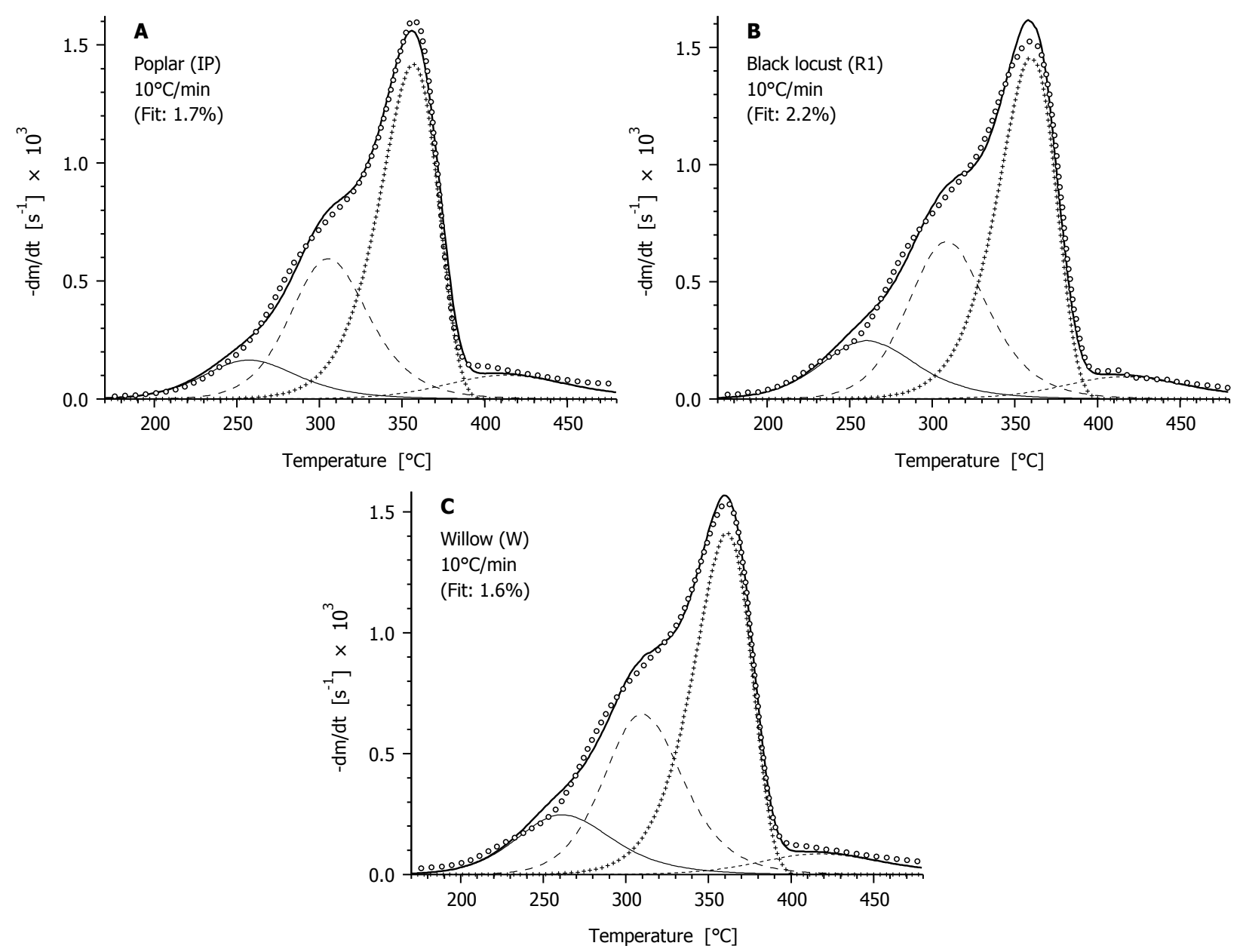

Figure 10. Comparison between the observed ( $\circ$ o o) and simulated (-) DTG curves at $10^{\circ} \mathrm{C} / \mathrm{min}$ employing the $n$th order model. Thin lines of different styles and symbol + denote the simulated curves of the partial reactions. (See Table 8. The peaks are numbered from left to right.)

Remarks on the Models and their $\boldsymbol{E}$ Values. The two models employed in the paper describe the inhomogeneity of the biomass components in different ways. The $1^{\text {st }}$ order model has two advantages:

(i) the shape of the partial curves attributed to hemicellulose and lignin looks more similar to that observed for an isolated hemicellulose ${ }^{12,15}$ and various lignins ${ }^{21,38,39}$ than the $2^{\text {nd }}$ order peaks of the second model;

(ii) the $1^{\text {st }}$ order terms are easier to be coupled to transport equations if they are used in models for industrial processes.

It is interesting to note that the difference in the kinetic description influenced only slightly the kinetic parameters of the two highest partial peaks, which were less overlapped by their neighbors than the 
smaller ones. The highest peak, due to cellulose decomposition, proved to be a $1^{\text {st }}$ order reaction in the $n$th order model, too, and the $E$ and $\log _{10} A$ parameters were practically identical in the two cases: $E=188$ and $187 \mathrm{~kJ} / \mathrm{mol}$ with $\log _{10} A=13.6$ and 13.4 , respectively. The second highest peak, attributed mainly to hemicellulose decomposition, had $E=165$ and $167 \mathrm{~kJ} / \mathrm{mol}$ with $\log _{10} A=12.6$ and 13.0 , while $n$ was 1 and 2, respectively. A wide range of activation energies has been reported in the literature of biomass materials. ${ }^{10,12-23,40}$ The above values are not far from the ones presented by Teng et al. for the cellulose and hemicellulose components in the pyrolysis of untreated rice hulls. ${ }^{10,17}$ However, our activation energies obtained for the lignin component, $84 \mathrm{~kJ} / \mathrm{mol}$ at $n=1$ and $146 \mathrm{~kJ} / \mathrm{mol}$ at $n=2$, are considerably higher than the ones reported in most similar biomass studies. ${ }^{10,17,19-23}$ The low activation energies presented frequently in the literature $(20-50 \mathrm{~kJ} / \mathrm{mol})$ arose from the formal approximation of a very broad range of processes by a single peak. One could expect much higher real activation energies for the high temperature partial processes, accordingly the values of the present work might be closer to the mean of the true activation energies of the various reactions in the lignin component.

Details on the Handling of Parameters $\delta m(\infty)$ and $\delta T$. As described above, the magnitude of the $\delta m(\infty)$ and $\delta T$ parameters were constrained into physically meaningful ranges by choosing appropriate $\lambda$ values in eq 8 . Table 9 shows how the decrease of the forces from the accepted values by a factor of $1 / 4$, and the complete removal of the penalties affect the results. Each tabulated value is the square root of the mean squares of the corresponding quantities. The denomination indicates how many items were used in the averaging. The fit only slightly changes as the penalties are removed. The alterations in the kinetic parameters, $E$ and $\log _{10} A$ are not higher than the scattering observed in a round-robin study on the kinetics of a single, sharp, well-defined peak. ${ }^{34}$ The change of the $c$ parameters is significant only in the penalty-free minimization of the 6-peak model. Accordingly, the main effect of the penalty is the constraint of the $\delta m(\infty)$ and $\delta T$ parameters into a range of physically meaningful values. 
Table 9. Effect of the Penalty Force on the Results ${ }^{\text {a }}$

\begin{tabular}{lcccccc} 
Model & \multicolumn{3}{c}{6 first-order peaks } & \multicolumn{3}{c}{$4 n$th order peaks } \\
$\lambda_{m}$ & $10^{-3}$ & $0.25 \times 10^{-3}$ & 0 & $10^{-3}$ & $0.25 \times 10^{-3}$ & 0 \\
$\lambda_{T}$ & $5 \times 10^{-7}$ & $1.25 \times 10^{-7}$ & 0 & $5 \times 10^{-7}$ & $1.25 \times 10^{-7}$ & 0 \\
\hline$\|\underline{\mathrm{fit}}\| / 12^{0.5}$ & 1.52 & 1.48 & 1.46 & 1.69 & 1.61 & 1.59 \\
$\|\underline{\mathrm{\delta} \mathrm{m}(\infty)}\| / 12^{0.5}$ & 0.008 & 0.014 & 0.023 & 0.007 & 0.014 & 0.022 \\
$\|\underline{\underline{\delta \mathrm{T}}}\| / 12^{0.5}$ & 2.2 & 2.7 & 3.8 & 3.4 & 4.4 & 5.0 \\
$\left\|\underline{\mathrm{E}}-\underline{\mathrm{E}}_{\mathrm{a}}\right\| / \mathrm{M}^{0.5}$ & - & 4 & 9 & - & 6 & 9 \\
$\| \log 10 \underline{\mathrm{A}}-\log _{10} \underline{\mathrm{A}_{\mathrm{a}} \| / \mathrm{M}^{0.5}}$ & - & 0.3 & 0.7 & - & 0.5 & 0.7 \\
$\|\underline{\underline{\mathrm{c}}}-\underline{\underline{\mathrm{c}}}\| / /(12 \mathrm{M})^{0.5}$ & - & 0.01 & 0.03 & - & 0.01 & 0.01
\end{tabular}

${ }^{a}$ Three different penalty force levels are shown. Subscript $a$ denotes the accepted parameters, belonging to $\lambda_{m}=10^{-3}$ and $\lambda_{T}=5 \times 10^{-7}$. The listed values are square roots of mean squares. See the Nomenclature for the symbols and units.

\section{Conclusions}

(1) The products of an experimental plantation for energy crops were investigated. Young shoots of hardwood samples (poplar, black locust and willow), and an herbaceous plant (Miscanthus sinensis) revealed unexpectedly similar thermal behavior in inert and oxidative atmospheres, as well. A poplar sample stored under industrial conditions, exposed to weather changes for a longer period, did not differ significantly from the poplar samples collected directly for this study and dried under laboratory circumstances.

(2) An eightfold difference in the level of grinding did not result in substantial differences in the thermal decomposition. The thermal decomposition of samples ground to $\leq 1 \mathrm{~mm}$ and to $\leq 0.120 \mathrm{~mm}$ could be described by the same kinetic model, with the same kinetic parameters.

(3) The effect of oxygen in the ambient gas was studied at low sample masses $(0.2-0.4 \mathrm{mg})$ that excluded the overheating due to the high reaction heat of the combustion process. The presence of oxygen affects the decomposition from ca. $220^{\circ} \mathrm{C}$. Nevertheless, the extrapolated onset temperature of the hemicellulose decomposition is practically the same at 0,5 and $21 \mathrm{~V} / \mathrm{V} \%$ oxygen in the flushing gas. 
It can be inferred that the start of the hemicellulose decomposition, around $248^{\circ} \mathrm{C}$, is not influenced by the presence of oxygen.

(4) A group of 12 experiments, representing two plant families, three genera, two grinding levels and four different heating programs were evaluated simultaneously by the method of least squares employing the model of independent pseudocomponents. All evaluated experiments were well described by the same set of kinetic parameters; only the parameters describing the peak area of the partial processes differed.

(5) A technique was recommended for the appropriate handling of the non-random errors in the simultaneous evaluation of experiment series by the method of least squares.

(6) When the partial processes were described by $1^{\text {st }}$ order kinetics, the assumption of six partial reactions was necessary for the proper description of the series evaluated. The identification of the partial reactions was based on the characteristics of the corresponding partial peaks appearing at linear temperature programs. The emergence of six partial peaks was connected to the use of stepwise and linear temperature programs in the series evaluated; the wider range of the experimental conditions reveals more of the chemical inhomogeneities of the biomass components.

(7) The application of $n$th order kinetics offered an alternative for the description of the chemical inhomogeneities of the hemicellulose and lignin components; this sort of modeling resulted in a good fit of the DTG curves by assuming only four pseudocomponents.

(8) The characteristics of the TG/DTG curves and the reaction kinetic modeling revealed a marked similarity of the samples. Keeping in mind the larger differences reported for hardwoods in other studies and the well-known influence of the inorganic constituents on the thermal behavior, we think that further investigations would be needed to clarify the effects of the age of the plants and soil conditions on the thermal behavior of plant materials. 


\section{Acknowledgement}

This work was supported by the Ministry of Environmental Protection (Grant 27753-022001) and by the Hungarian National Research Fund (OTKA T37705, T37704, and T25347). The authors are grateful to Dr. Piroska Szabó and Ms. Linda Nemes for their help.

\section{NOMENCLATURE}

$\|\ldots\| \quad \mathrm{L}_{2}$ norm

$\|\ldots\| / \mathrm{M}^{1 / 2}$ square root of mean squares of a vector or matrix of $\mathrm{M}$ elements

$\alpha \quad$ reacted fraction of a pseudocomponent

$\lambda_{\mathrm{m}}, \lambda_{\mathrm{T}} \quad$ multiplier factors in eq 8

A pre-exponential factor $\left(\mathrm{s}^{-1}\right)$

c normalized mass of volatiles formed from a pseudocomponent

E activation energy $(\mathrm{kJ} / \mathrm{mol})$

f factors expressing differences between the $\underline{\mathrm{c}}$ vectors of a given species

fit $\quad 100 \mathrm{~s}^{0.5}(\%)$

h height of $\mathrm{a}-\mathrm{dm}^{\text {obs }} / \mathrm{dt}$ curve

$\mathrm{m}^{\text {calc }}(\mathrm{t}) \quad$ normalized sample mass calculated from a model

$\mathrm{m}^{\mathrm{obs}}(\mathrm{t}) \quad$ mass of the sample divided by the initial sample mass

$\mathrm{m}_{500^{\circ} \mathrm{C}} \quad$ char yield at $500^{\circ} \mathrm{C}$

$\mathrm{m}(\infty) \quad \mathrm{m}^{\mathrm{calc}}(\mathrm{t})$ at $\mathrm{t}=\infty$

$\delta m(\infty)$ correction term to describe small experimental and model errors

M number of pseudocomponents

$\mathrm{n} \quad$ parameters affecting the shape of a partial curve in eq 2

$\mathrm{N} \quad$ number of evaluated data on an experimental curve

$\mathrm{R} \quad$ gas constant $\left(8.3143 \times 10^{-3} \mathrm{~kJ} \mathrm{~mol}^{-1} \mathrm{~K}^{-1}\right)$

s least squares sum for one experiment 


$\begin{array}{ll}\mathrm{S} & \text { least squares sum for a series of experiments } \\ \mathrm{t} & \text { time (s) } \\ \mathrm{T} & \text { temperature }\left({ }^{\circ} \mathrm{C}, \mathrm{K}\right) \\ \mathrm{T}_{\text {hc.onset }} & \text { onset temperature extrapolated from the section of the DTG curves } \\ & \text { dominated by hemicellulose decomposition } \\ \mathrm{T}_{\text {offset }} & \quad \text { extrapolated offset temperature } \\ \mathrm{T}_{\text {peak }} & \text { temperature belonging to the maximum of a }-\mathrm{dm} / \mathrm{dt} \text { or a d } \alpha_{\mathrm{j}} / \mathrm{dt} \text { curve } \\ \delta \mathrm{T} & \text { temperature correction term }\end{array}$

\section{Subscripts:}

$\begin{array}{ll}\text { a } & \text { accepted results } \\ \text { i } & \text { digitized point on an experimental curve } \\ \text { j } & \text { pseudocomponent } \\ \text { p } & \text { temperature program } \\ \text { s } & \text { species }\end{array}$

\section{References}

(1) Broido, A. Kinetics of Solid-Phase Cellulose Pyrolysis. In Thermal Uses and Properties of Carbohydrates and Lignins; Shafizadeh, F., Sarkanen, K.V., Tillman, D.A., Eds.; Academic Press: New York, 1976; pp. 19-35.

(2) Shafizadeh, F. Introduction to Pyrolysis of Biomass. J. Anal. Appl. Pyrol. 1982, 3, 283 - 305.

(3) Shafizadeh, F. In The Chemistry of the Solid Wood. Rowell, R. M., Ed. in Advances in Chemistry Series 207. Comstock, M. J., Series Ed.; Am. Chem. Soc, 1984; pp. 489 - 529.

(4) Antal, M. J. Biomass Pyrolysis: A Review of the Literature. Part I. Carbohydrate pyrolysis. In Advances in Solar Energy; Boer, K. W., Duffie, J. A., Eds.; American Solar Energy, Inc.: Boulder, CO, 1982; pp. 61-111.

(5) Antal, M. J. Biomass Pyrolysis: A Review of the Literature. Part II. Lignocellulose Pyrolysis. In Advances in Solar Energy; Boer, K. W., Duffie, J. A., Eds.; American Solar Energy Society: Boulder, CO, 1985.

(6) Evans, R.J.; Milne, T. A. Molecular Characterization of the Pyrolysis of Biomass. 1. Fundamentals. Energy Fuels 1987, 1, 123 - 137. 
(7) DeGroot, W. F.; Pan, W.-P., Rahman, M. D.; Richards, G. N. First Chemical Events in the Pyrolysis of Wood. J. Anal. Appl. Pyrol. 1988, 13, 221-231.

(8) Várhegyi, G.; Antal, M. J., Jr.; Székely, T.; Till, F.; Jakab, E.; Szabó, P. Simultaneous

Thermogravimetric - Mass Spectrometric Studies on the Thermal Decomposition of Biopolymers. Part 2: Sugar Cane Bagasse in the Presence and Absence of Catalysts. Energy Fuels 1988, 2, 273-277.

(9) Senneca, O.; Chirone, R.; Salatino, P. A. Thermogravimetric Study of Nonfossil Solid Fuels. 2. Oxidative Pyrolysis and Char Combustion. Energy Fuels 2002, 16, 661 - 668.

(10) Teng, H., Wei, Y. C. Thermogravimetric Studies on the Kinetics of Rice Hull Pyrolysis and the Influence of Water Treatment. Ind. Eng. Chem. Res. 1998, 37, 3806-3811.

(11) Sjöström, E. Wood Chemistry. Academic Press: New York, 1981.

(12) Várhegyi, G.; Antal, M. J., Jr.; Székely, T.; Szabó, P. Kinetics of the Thermal Decomposition of Cellulose, Hemicellulose and Sugar Cane Bagasse. Energy Fuels 1989, 3, 329-335.

(13) Várhegyi, G.; Szabó, P.; Antal, M. J., Jr. Reaction Kinetics of the Thermal Decomposition of Cellulose and Hemicellulose in Biomass Materials. In Advances in Thermochemical Biomass Conversion (Ed. by A. V. Bridgwater), Volume 2, Chapman and Hall: London, 1994, pp. 760-771. (14) Caballero, J. A.; Font, R.; Marcilla, A. Comparative Study of the Pyrolysis of Almond Shells and their Fractions, Holocellulose and Lignin. Product Yields and Kinetics. Thermochim. Acta 1996, 276, 57-77.

(15) Várhegyi, G.; Antal, M. J.; Jakab, E.; Szabó, P. Kinetic Modeling of Biomass Pyrolysis, J. Anal. Appl. Pyrol. 1997, 42, 73-87.

(16) Caballero, J. A.; Conesa, J. A.; Font, R.; Marcilla, A. Pyrolysis Kinetics of Almond Shells and Olive Stones Considering their Organic Fractions. J. Anal. Appl. Pyrol. 1997, 42, 159-175.

(17) Teng, H.; Lin, H. C., Ho, J. A. Thermogravimetric Analysis on Global Mass Loss Kinetics of Rice Hull Pyrolysis. Ind. Eng. Chem. Res. 1997, 36, 3974-3977.

(18) Órfão, J. J. M.; Antunes, F. J. A.; Figueiredo, J. L. Pyrolysis Kinetics of Lignocellulosic Materials - 3 Independent Reactions Model. Fuel 1999, 78, 349-358.

(19) Helsen, L.; Van den Bulck, E. Kinetics of the Low-Temperature Pyrolysis of Chromated Copper Arsenate-Treated Wood. J. Anal. Appl. Pyrol. 2000, 53, 51-79.

(20) Sørum, L.; Grønli, M. G.; Hustad, J. E. Pyrolysis Characteristics and Kinetics of Municipal Solid Wastes, Fuel 2001, 80, 1217-1227.

(21) Grønli, M. G.; Várhegyi, G.; Di Blasi, C. Thermogravimetric Analysis and Devolatilization Kinetics of Wood. Ind. Eng. Chem. Res. 2002, 41, 4201-4208.

(22) Vamvuka, D.; Pasadakis, N.; Kastanaki E. Kinetic Modeling of Coal/Agricultural By-Product Blends. Energy Fuels 2003, 17, 549 -558. 
(23) Manyà, J. J.; Velo, E.; Puigjaner, L. Kinetics of biomass pyrolysis: A Reformulated Threeparallel-reactions Model. Ind. Eng. Chem. Res. 2003, 42, 434-441.

(24) Coombs, J.; Hall, K. Chemicals and Polymers from Biomass. Renewable Energy 1998, 15, 54 59.

(25) Marosvölgyi, B.; Halupa, L.; Wesztergom, I. Poplars as Biological Energy Sources in Hungary. Biomass Bioenergy 1999, 16, 245 - 247.

(26) Rafaschieri, A.; Rapaccini, M.; Manfrida, G. Life Cycle Assessment of Electricity Production from Poplar Energy Crops Compared with Conventional Fossil Fuels. Energy Conversion Management 1999, 40, 1477 - 1493.

(27) Senelwa, K.; Sims, R. E. H. Fuel Characteristics of Short Rotation Forest Biomass. Biomass Bioenergy 1999, 17, 127 - 140.

(28) Kataki, R.; Konwer, D. Fuelwood Characteristics of Some Indigenous Woody Species of NorthEast India. Biomass Bioenergy 2000, 20, 17 - 23.

(29) Bilbao, R; Mastral, J. F.; Aldea, M. E.; Ceamanos, J. The Influence of the Percentage of Oxygen in the Atmosphere on the Thermal Decomposition of Lignocellulosic Materials. J. Anal. Appl. Pyrol. 1997, 42, 189-202.

(30) Liu, N. A.; Fan, W. C.; Dobashi, R.; Huang, L. S. Kinetic Modeling of Thermal Decomposition of Natural Cellulosic Materials in Air Atmosphere. J. Anal. Appl. Pyrol. 2002, 63, 303-325.

(31) Várhegyi, G.; Jakab, E.; Antal, M. J., Jr. Is the Broido - Shafizadeh Model for Cellulose Pyrolysis True? Energy Fuels 1994, 8, 1345-1352.

(32) Press, W. H.; Flannery, B. P.; Teukolsky, S. A.; Vetterling, W. T. Numerical Recipes. The Art of Scientific Computing. 2nd ed., Cambridge University Press: Cambridge (U.K.), 1992. (Online Internet edition: http://www.ulib.org/webRoot/Books/Numerical_Recipes.)

(33) Antal, M. J., Jr.; Grønli, M. M. G. The Art, Science, and Technology of Charcoal Production. Ind. Eng. Chem. Res. 2003, 42, 1619-1640.

(34) Grønli, M.; Antal, M. J., Jr.; Várhegyi, G. A Round-Robin Study of Cellulose Pyrolysis Kinetics by Thermogravimetry. Ind. Eng. Chem. Res. 1999, 38, 2238-2244.

(35) Várhegyi, G.; Szabó, P.; Jakab, E.; Till, F.; Richard, J. F. Mathematical Modeling of Char Reactivity in Ar- $\mathrm{O}_{2}$ and $\mathrm{CO}_{2}-\mathrm{O}_{2}$ Mixtures. Energy Fuels 1996, 10, 1208-1214.

(36) Várhegyi, G.; Pöppl, L.; Földvári, I. Kinetics of the Oxidation of Bismuth Tellurite, $\mathrm{Bi}_{2} \mathrm{TeO}_{5}$ : Empirical Model and Least Squares Evaluation Strategies to Obtain Reliable Kinetic Information. Thermochim. Acta 2003, 399, 225-239.

(37) Tikhonov, A.; Arsénine, V. Méthodes de Résolution de Problèmes Mal Posés. Éditions Mir, Moscow, 1976. 
(38) Jakab, E.; Faix, O.; Till, F.; Székely, T. Thermogravimetry/Mass Spectrometry Study of Six

Lignins Within the Scope of an International Round Robin Test. J. Anal. Appl. Pyrol. 1995, 35, 167179.

(39) Jakab, E.; Faix, O.; Till, F. Thermal Decomposition of Milled Wood Lignins Studied by Thermogravimetry/Mass Spectrometry. J. Anal. Appl. Pyrol. 1997, 40-41, 171-186.

(40) Antal, M. J.; Várhegyi, G.; Jakab, E. Cellulose Pyrolysis Kinetics: Revisited. Ind. Eng. Chem. Res. 1998, 37, 1267-1275. 